\title{
Knowledge, Attitude and Practice (KAP) Survey of Osteoporosis among Students of a Tertiary Institution in Malaysia
}

\author{
Yusra Habib Khan*, Azmi Sarriff, Amer Hayat Khan and Tauqeer Hussain Mallhi \\ School of Pharmaceutical Sciences, University Sains Malaysia (USM). Pulau Penang 11800 Malaysia
}

*For correspondence: Email: yusrahabib@ymail.com; Tel: 006-0164530979

Received: 8 December 2012

Revised accepted: 1 November 2013

\begin{abstract}
Purpose: To evaluate knowledge and perceptions of osteoporosis among university students in Malaysia belonging to different age groups, gender and ethnicity.

Methods: Using convenience sampling method, current study was conducted among students of University Sains Malaysia (USM), Pulau Penang, Malaysia. A pre-validated self- administered questionnaire was used to carry out the study.

Results: The mean age of the participants was $24.61 \pm 5.51$ years. A majority, 401 (87\%), identified osteoporosis correctly as a disease that makes bones weak and fragile. Lack of milk and dairy products were identified by majority of participants (74\%) as a risk factor for osteoporosis while being petite (24 $\%)$ and family history (34.5\%) were the least identified risk factors. Female showed statistically higher knowledge score than males (243.89 versus 216.12, $p=0.02)$. Ethnicity (Malay: 228.32, Chinese: 264.46, Indian: 194.04, Others: 236.94, $p=0.00$ ) and type of education (Hybrid: 225.99, Arts: 182.21, Science: 286.23, $p=0.00$ ) were factors that correlated significantly with knowledge and perceptions of osteoporosis.

Conclusion: This study demonstrates an urgent need for the implementation of educational and awareness programs for university students belonging to various age groups. Such programs should be designed on the basis of the parameters of health belief model.
\end{abstract}

Keywords: Attitude, Bones, Knowledge, Osteoporosis, Practice, University students.

Tropical Journal of Pharmaceutical Research is indexed by Science Citation Index (SciSearch), Scopus, International Pharmaceutical Abstract, Chemical Abstracts, Embase, Index Copernicus, EBSCO, African Index Medicus, JournalSeek, Journal Citation Reports/Science Edition, Directory of Open Access Journals (DOAJ), African Journal Online, Bioline International, Open-J-Gate and Pharmacy Abstracts

\section{INTRODUCTION}

One of the most common metabolic diseases that show their clinical manifestations only after sufficient damage has been done is osteoporosis. Osteoporosis, as defined by National Institute of Health $(\mathrm{NIH})$, is a skeletal disorder characterized by compromised bone strength predisposing to an increased risk of fracture [1].

The prevalence of osteoporosis has reached to endemic proportions [2]. As projected by WHO, approximately 75 million people in Europe and America are suffering from osteoporosis and worldwide 9 million fractures are solely due to osteoporosis every year [3]. Although osteoporosis is more prevalent among Caucasians, it has been estimated that by 2050 , more than 50 percent of all osteoporotic fractures will occur in Asia [4]. According to Arthritis Foundation of Malaysia, it has been estimated that more than 1 million Malaysians are at risk of developing osteoporosis, of which 20 percent are men [5] while 51.8 percent of urban Malaysian women suffer from osteoporosis near the age of menopause [6]. 
The word, 'osteoporosis', brings to mind the stereotype of an old gloomy over-hunched woman in her late fifties [7] but it is no longer considered to be due to aging alone. Lifestyle choices, certain diseases and medications can cause this condition even in children, adults, men and premenopausal women [8]. Since osteoporosis can occur at any age, it is extremely crucial to attain maximum peak bone mass during adolescence [9] as the amount of bone mass achieved during that age determines the quality of bones in later life.

Various studies have been conducted to evaluate knowledge, attitude and practices (KAP) of osteoporosis in different geographical settings with varied community population. Due to the varying nature of instruments and methodology used, it is not possible to compare these studies. However, there are some that are worth mentioning their limitations. Most of the studies that have been conducted previously do not use a validated questionnaire to assess KAP [10,1114] and the main focus of those studies was women who were already suffering from osteoporosis [15]. It must be noticeable that those who are already suffering from a disease or under treatment of a particular disease would have better knowledge of disease as they are in direct contact with health care professionals. Hence, the results of such studies cannot be generalized for whole population. A few studies were conducted on both elderly men and women but in most cases sample size was not adequate $[13,16,17]$. Very few studies have been conducted on adolescence females [10,12-14], and even fewer studies evaluated KAP regarding osteoporosis in both genders at adolescence [18].One of the biggest flaws of a majority of the studies was absence of scoring system. As KAP studies are conducted to evaluate knowledge level, varying attitudes and practices towards a disease, it is important to conclude where the study population stands in terms of knowledge or how good or bad knowledge or practices were as it would help to design specific interventional strategies for that particular population.

The aim of the current study was to evaluate knowledge and perceptions of osteoporosis among university students in a tertiary educational institution in Malaysia based on age group, gender and ethnicity. Secondly, in order to categorize and co-relate knowledge, attitude and practices of the study population, this study aimed to develop a scoring system.

\section{METHODS}

\section{Study location}

The current study is an exploratory crosssectional study conducted at University Sains Malaysia (USM), Pulau Penang, Malaysia. The population of Malaysia varies from one state to the other, but three major races, namely, Malay, Chinese and Indian, exist throughout Malaysia. According to the 2010 census, Penang is a multiracial state with diverse ethnic composition as follow: Chinese $45.6 \%$, Malays $43.6 \%$, Indians $10.4 \%$ and others $0.4 \%$ [19].. Due to limited availability of resources, time and complex nature of study, current study is directed to the cited state i.e. Penang Island.

\section{Sample size}

Calculation of sample size was done to ensure the minimum number of respondents needed to be a representative sample for the whole population of Penang. The sample size was determined using Raosoft sample size calculator [20]. Keeping an indicator percentage of 0.50 , margin of error of $5 \%$ and confidence interval (Cl) of $95 \%$, the calculated sample size was 384 .

\section{Questionnaire}

Although the questionnaire used for assessing KAP consisted of three main domains, viz, knowledge, attitude and practices, in order to have a better assessment of overall knowledge regarding disease, questions in knowledge section were further divided into 3 main sections. The first four questions of knowledge section were general questions related to osteoporosis, while a list of 10 most significant risk factor of osteoporosis were given in question 5. Question 6 comprises three most common complications of osteoporosis. The attitude and practice section of questionnaire consist of 10 questions each.

Each correct answer in the knowledge domain carried 1 mark while wrong or don't know carried 0 mark. This gave a total score range of $0-17$ for knowledge section. In attitude section, neutral carried 0 mark while positive attitude such as definitely agree and moderately agree carried a score of "2" and "1", respectively. Negative attitude such as moderately disagree and definitely disagree were given "- 1 " and "-2", respectively. This gave a score range of -20 to +20 for attitude section. In the case of practice section, 'Never' was scored 0 while 'Rarely', 'Sometimes', 'Frequently' and 'Always' were scored as "1", "2", "3", and" 4", respectively. 'Always' shows maximum frequency for an event, 
and therefore it was assigned the highest score. This gave a score range of 0 to 40 to practice section. In case of negatively quoted questions, reverse scoring was used. The scores in knowledge, attitude and practice domains were categorized as poor (less than and equal to 50 $\%$ ), fair (51 to $69 \%$ ) and good (70 \% and above).

\section{Validation of questionnaire}

The questionnaire was thoroughly reviewed by a panel comprising health care professionals (3 trainee orthopedic specialists, 2 physicians, 5 hospital pharmacists, 3 community pharmacists) and 5 lecturers from Pharmacy Department of USM. The purpose of this content validation was to ensure the questions were not ambiguous and content was appropriate. Based on panel reviews, modifications were carried out with regard to arrangement and structure of questions. Moreover, to ensure reliability, a pilot study was conducted among randomly selected university students $(n=30)$. A test-retest method was utilized. Same group of students was asked to fill same questionnaire after 10 days interval.

\section{Study design}

Students from all over the university were broadly divided into 3 main schools i.e. , Schools of Pure Arts, Applied Arts and Sciences based on the existing administrative divisions of the university. Students from all schools were provided with questionnaire by a researcher.. After explaining the purpose of study briefly, students were requested to fill in the questionnaire along with the consent form. Fifteen minutes later, the questionnaire were either taken back by a researcher or returned by students themselves.

\section{Statistical analysis}

For analysis of data, Statistical Package for Social Sciences software, version 16.0 (SPSS Inc., Chicago, IL) was used. Initially, all information gathered via questionnaire was coded into variables. Normality of data was tested using Kolmogorov-Smirnov test. Both descriptive and inferential statistics involving Chisquare test, Mann-Whitney U test, Kruskal Wallis $\mathrm{H}$ test and binary regression were used to present results. For each test, a $p$-value of less than 0.05 was considered statistically significant.

\section{RESULTS}

The reliability results of the questionnaire showed that there was no statistically significant difference between results of both pilot studies.
The Cronbach's alpha of the questionnaire was 0.79. For individual domains, maximum Cronbach's alpha was for knowledge section followed by attitude and practices section. The reason for low Cronbach's alpha for attitude and practice domain might be due to less number of questions as compared to knowledge section.

A total of 500 questionnaires were distributed and 461 returned, giving a response rate of 92 $\%$. A very high response rate might be due to face to face personnel meeting of researcher with study respondents. Non-respondents were not followed up. The demographic profile of study participants including frequencies for gender, ethnicity, marital status, education level along with type of school is shown in Table1. The age of the participants ranged from 19 years to 47 years with mean age \pm S.D of $24.61 \pm 5.51$ years.

Table 1: Demographic profile of study participants

\begin{tabular}{lc}
\hline Variable & $\mathbf{N}(\%)$ \\
\hline $\begin{array}{l}\text { Age (mean } \pm \text { SD) } \\
\text { Gender } \\
\text { Male }\end{array}$ & $24.61+5.51$ \\
$\quad$ Female & $214(46.4 \%)$ \\
Ethnicity & $247(53.6 \%)$ \\
$\quad$ Malay & \\
$\quad$ Chinese & $165(35.8 \%)$ \\
$\quad$ Indian & $147(31.9 \%)$ \\
$\quad$ Others & $125(27.1 \%)$ \\
Marital status & $24(5.2 \%)$ \\
$\quad$ Single & \\
Married & $409(88.7 \%)$ \\
Education & $52(11.3 \%)$ \\
$\quad$ Undergraduate & $294(63.8 \%)$ \\
$\quad \begin{array}{l}\text { Postgraduate } \\
\text { School }\end{array}$ & $167(36.2 \%)$ \\
$\quad \begin{array}{l}\text { Applied Arts } \\
\text { Pure Arts }\end{array}$ & $155(33.6 \%)$ \\
$\quad$ Sciences & $155(33.6 \%)$ \\
Diagnosis with & $151(32.8 \%)$ \\
bone problem & \\
No & \\
Yes &
\end{tabular}

Descriptive statistics for each item in the questionnaire are given in Table 2. In knowledge section, a majority, 401 (87 \%), identified osteoporosis correctly as a disease that makes bones weak and fragile while least 197 (42.7\%) participants were able to correctly identify that osteoporosis does not affect both genders equally. A majority of $171(37.1 \%)$ answered don't know for gender question while 93 (20.25 $\%$ ) answered that osteoporosis affect both genders equally. In case of risk factors, a majority of 340 (73.8 \%) identified lack of milk and dairy products followed by lack of exercise $312(67.7 \%)$ and being female 270 (58.6 \%) as risk factor for development of osteoporosis. 
Being short and thin 110 (23.9\%) and family history of osteoporosis 159 (34.5\%) were least identified risk factors. The only risk factor that a majority $231(50.1 \%)$ answered 'don't know' was avoidance of sunlight. As far as complications are concerned, a majority of 389 (84.4\%) identified bone fractures as a complication of osteoporosis while slouched body posture was identified by 179 (38\%) number of participants. In attitude section, 137 (29\%) agreed that very strict dieting can cause osteoporosis while a majority of $224(48 \%)$ agreed that chronic back pain is normal with aging. Similarly negative attitudes were observed in questions related to diagnosis of osteoporosis i.e. question 5, 6 and 9. However, 256 (55\%) participants agreed that they are concerned about getting osteoporosis. The frequencies for practice questions showed that majority of participants $56 \%$ had rarely discussed osteoporosis with family as well as health care professionals. A large number identified friends and relatives $(n=131,28.8 \%)$ followed by television $(n=109,23.6 \%$ ) as their source of information while only $31(6.7 \%)$ identified health care professionals as their source of information.

Table 2: Frequency of various responses to questions

\begin{tabular}{|c|c|c|c|c|c|c|}
\hline Domain & $\begin{array}{l}\text { Item } \\
\text { no. }\end{array}$ & Yes & \multicolumn{2}{|c|}{ No } & \multicolumn{2}{|c|}{ Don't know } \\
\hline \multirow[t]{4}{*}{ Knowledge } & 1 & $401(87 \%)$ & \multicolumn{2}{|c|}{$19(4.1 \%)$} & \multicolumn{2}{|l|}{$41(8.9 \%)$} \\
\hline & 2 & $295(64 \%)$ & \multicolumn{2}{|c|}{$82(4.1 \%)$} & \multicolumn{2}{|l|}{$84(18.2 \%)$} \\
\hline & 3 & $294(63.8 \%)$ & \multicolumn{2}{|c|}{$86(17.8 \%)$} & \multicolumn{2}{|c|}{$81(17.6 \%)$} \\
\hline & 4 & $197(42.7 \%)$ & \multicolumn{2}{|c|}{$93(20.25)$} & \multicolumn{2}{|l|}{$171(37.1 \%)$} \\
\hline \multirow[t]{10}{*}{ Risk factors } & $5 a$ & $340(73.8 \%)$ & \multicolumn{2}{|c|}{$66(14.3 \%)$} & \multicolumn{2}{|c|}{$55(11.9 \%)$} \\
\hline & $5 b$ & $185(40.1 \%)$ & \multicolumn{2}{|c|}{$159(34.5 \%)$} & \multicolumn{2}{|l|}{$117(25.4 \%)$} \\
\hline & $5 c$ & $159(34.5 \%)$ & \multicolumn{2}{|c|}{$117(25.4 \%)$} & \multicolumn{2}{|c|}{$185(40.1 \%)$} \\
\hline & $5 d$ & $270(58.6 \%)$ & \multicolumn{2}{|c|}{$95(20.6 \%)$} & \multicolumn{2}{|l|}{$96(20.8 \%)$} \\
\hline & $5 e$ & $162(35.1 \%)$ & \multicolumn{2}{|c|}{$68(14.8 \%)$} & \multicolumn{2}{|c|}{$231(50.1 \%)$} \\
\hline & $5 f$ & $202(43.8 \%)$ & \multicolumn{2}{|c|}{$62(13.4 \%)$} & \multicolumn{2}{|c|}{$197(42.7 \%)$} \\
\hline & $5 g$ & $312(67.7 \%)$ & \multicolumn{2}{|c|}{$80(17.4 \%)$} & \multicolumn{2}{|c|}{$69(15 \%)$} \\
\hline & $5 \mathrm{~h}$ & $268(58.1 \%)$ & & $4(22.6 \%)$ & $89(19.3 \%)$ & \\
\hline & $5 i$ & $110(23.9 \%)$ & & $(50.1 \%)$ & $120(26 \%)$ & \\
\hline & $5 j$ & $253(54.9 \%)$ & & $(23.9 \%)$ & $98(21.3 \%)$ & \\
\hline Complications & $6 a$ & $389(84.4 \%)$ & & $(5.6 \%)$ & $46(10 \%)$ & \\
\hline & $6 b$ & $203(44 \%)$ & & $7(38.4 \%)$ & $81(17.6 \%)$ & \\
\hline & $6 c$ & $179(38 \%)$ & & $(18.9 \%)$ & $195(42.3 \%$ & \\
\hline Attitude & & $\begin{array}{l}\text { Definitely } \\
\text { agree }\end{array}$ & $\begin{array}{l}\text { Moderately } \\
\text { agree }\end{array}$ & Neutral & $\begin{array}{l}\text { Moderately } \\
\text { disagree }\end{array}$ & $\begin{array}{l}\text { Definitely } \\
\text { disagree }\end{array}$ \\
\hline & 1 & $36(7.8 \%)$ & $101(21.9 \%)$ & $212(46 \%)$ & $84(18.2 \%)$ & $28(6.1 \%)$ \\
\hline & 2 & $77(16.7 \%)$ & $150(32.5 \%)$ & $188(40.8 \%)$ & $37(8 \%)$ & $9(2 \%)$ \\
\hline & 3 & $47(10.2 \%)$ & $98(21.3 \%)$ & $168(36.4 \%)$ & $96(20.8 \%)$ & $52(11.3 \%)$ \\
\hline & 4 & $35(7.6 \%)$ & $116(25.2 \%)$ & $175(38 \%)$ & $93(20.2 \%)$ & $42(9.1 \%)$ \\
\hline & 5 & $39(8.5 \%)$ & $96(20.8 \%)$ & $222(48.2 \%)$ & $47(10.2 \%)$ & $57(12.4 \%)$ \\
\hline & 6 & $20(4.3 \%)$ & $70(15.2 \%)$ & $296(64.2 \%)$ & $38(8.2 \%)$ & $37(8 \%)$ \\
\hline & 7 & $61(13.2 \%)$ & $163(35.4 \%)$ & $168(36.4 \%)$ & $54(11.7 \%)$ & $15(3.3 \%)$ \\
\hline & 8 & $38(8.2 \%)$ & $109(23.6 \%)$ & $204(44.3 \%)$ & $90(19.5 \%)$ & $20(4.3 \%)$ \\
\hline & 9 & $48(10.4 \%)$ & $124(26.9 \%)$ & $209(45.3 \%)$ & $70(15.2 \%)$ & $10(2.2 \%)$ \\
\hline & 10 & $119(25.8 \%)$ & $137(29.7 \%)$ & $140(30.4 \%)$ & $33(7.2 \%)$ & $32(6.9 \%)$ \\
\hline Practice & & Always & Frequently & Sometimes & Rarely & Never \\
\hline & 1 & $77(16.7 \%)$ & $84(18.2 \%)$ & $185(40.1 \%)$ & $95(20.6 \%)$ & $20(4.3 \%)$ \\
\hline & 2 & $94(20.4 \%)$ & $149(32.3 \%)$ & $160(34.7 \%)$ & $47(10.2 \%)$ & $11(2.4 \%)$ \\
\hline & 3 & $89(19.3 \%)$ & $129(28 \%)$ & $151(32.8 \%)$ & $75(16.3 \%)$ & $17(3.7 \%)$ \\
\hline & 4 & $96(20.8 \%)$ & $146(31.7 \%)$ & $132(28.6 \%)$ & $55(11.9 \%)$ & $28(6.1 \%)$ \\
\hline & 5 & $14(3 \%)$ & $41(8.9 \%)$ & $108(23.4 \%)$ & $155(33.6 \%)$ & $143(31 \%)$ \\
\hline & 6 & $1(0.2 \%)$ & $222(48.2 \%)$ & $0(0 \%)$ & $0(0 \%)$ & $238(51.6 \%)$ \\
\hline & 7 & $5(1.1 \%)$ & $5(1.1 \%)$ & $15(3.3 \%)$ & $8(1.7 \%)$ & $428(92.8 \%)$ \\
\hline & 8 & $2(0.4 \%)$ & $5(1.1 \%)$ & $23(5 \%)$ & $41(8.9 \%)$ & $390(84.6 \%)$ \\
\hline & 9 & $184(39.9 \%)$ & $91(19.7 \%)$ & $96(20.8 \%)$ & $66(14.3 \%)$ & $24(5.2 \%)$ \\
\hline & 10 & $105(22.8 \%)$ & $135(29.3 \%)$ & $145(31.5 \%)$ & $60(13 \%)$ & $16(3.5 \%)$ \\
\hline
\end{tabular}


Inferential statistics, i.e., Mann-Whitney $U$ and Kruskal Wallis $\mathrm{H}$ tests were applied to compare scores of each domain with various demographic factors. The results of the test are shown in Table 3. By taking $p<0.05$ as statistically significant, there was a difference between mean knowledge score of male (216.2) and female (243.89). Female showed higher knowledge than males. Similarly, for ethnicity, Chinese showed statistically significant higher mean knowledge and practice score than other races. Lastly, a significantly higher difference was observed between mean knowledge and attitude score for science than for students in pure and applied arts, with science students scoring maximum in both knowledge and attitude sections. No statistically significant difference in scores was observed among other demographic factors.

A correlation between different domains of questionnaire was also assessed. A weak positive correlation was observed between knowledge and attitude (Table 4).

Using chi-square test, for each domain scores of the study participants were categorized into 3 categories: good, fair and poor. The results of this categorization are shown in (Table 5).

Table 3: Mean score with respect to demographics
Table 4: Correlation between KAP

\begin{tabular}{lll}
\hline Variables & rho & $\boldsymbol{P}$-value \\
\hline Knowledge, attitude & 0.173 & $<0.001^{*}$ \\
Knowledge, practice & 0.074 & 0.112 \\
Practice, Attitude & 0.066 & 0.155 \\
\hline${ }^{*}$ Statistically significant at $p<0.05$ &
\end{tabular}

\section{DISCUSSION}

The current study differs from previously conducted KAP studies in certain respects. First, the present study enrolled participants with different age groups (19 years to 47 years).

Secondly, a scoring system was developed and scores of participants for each domain were analyzed and co-related with various demographic factors, also for each domain participants have been categorized according to their score. Another important prospect of this study was to evaluate various attitudes and practices of literate community towards osteoporosis and analysis of various practices that can serve as a risk factor for future development of osteoporosis.

The results of our study indicate that females showed better knowledge on osteoporosis than males. Same results were observed in previously

\begin{tabular}{|c|c|c|c|c|c|c|}
\hline Variable & $\begin{array}{l}\text { K.score } \\
9.51+2.15 \\
\text { Mean rank }\end{array}$ & $P$-value & $\begin{array}{l}\text { A.score } \\
0.646+3.25 \\
\text { Mean rank }\end{array}$ & $P$-value & $\begin{array}{l}\text { P.score } \\
24.21+4.25 \\
\text { Mean rank }\end{array}$ & $P$-value \\
\hline \multicolumn{7}{|l|}{ Gender } \\
\hline Male & 216.12 & \multirow[t]{2}{*}{0.024} & 239.81 & \multirow[t]{2}{*}{0.183} & 238.57 & \multirow[t]{2}{*}{0.255} \\
\hline Female & 243.89 & & 223.36 & & 224.44 & \\
\hline \multicolumn{7}{|l|}{ Ethnicity* $^{*}$} \\
\hline Malay & 228.32 & \multirow{4}{*}{0.00} & 244.78 & \multirow{4}{*}{0.262} & 240.49 & \multirow{4}{*}{0.00} \\
\hline Chinese & 264.46 & & 223.53 & & 253.65 & \\
\hline Indian & 194.04 & & 223.26 & & 189.05 & \\
\hline Others & 236.94 & & 222.33 & & 245.52 & \\
\hline \multicolumn{7}{|l|}{ Marital status } \\
\hline Single & 232.48 & \multirow[t]{2}{*}{0.498} & 232.89 & \multirow[t]{2}{*}{0.390} & 229.83 & \multirow[t]{2}{*}{0.594} \\
\hline Married & 219.34 & & 216.12 & & 240.24 & \\
\hline \multicolumn{7}{|l|}{ Education } \\
\hline Undergraduate & 237.84 & \multirow[t]{2}{*}{0.140} & 225.27 & \multirow[t]{2}{*}{0.217} & 233.12 & \multirow[t]{2}{*}{0.649} \\
\hline Postgraduate & 218.96 & & 241.09 & & 227.26 & \\
\hline \multicolumn{7}{|l|}{ School* } \\
\hline Hybrid $^{* *}$ & 225.99 & \multirow[t]{3}{*}{0.00} & 216.30 & \multirow[t]{3}{*}{0.00} & 214.83 & \multirow[t]{3}{*}{0.084} \\
\hline Arts & 182.21 & & 212.00 & & 230.06 & \\
\hline Science & 286.23 & & 265.59 & & 248.56 & \\
\hline \multicolumn{7}{|l|}{$\begin{array}{l}\text { Diagnosis with } \\
\text { bone problem }\end{array}$} \\
\hline Yes & & \multirow[t]{3}{*}{0.175} & & \multirow[t]{3}{*}{0.522} & & \multirow[t]{3}{*}{0.704} \\
\hline No & 194.67 & & 248.22 & & 220.74 & \\
\hline & 232.91 & & 230.10 & & 231.54 & \\
\hline
\end{tabular}

$P$-value $<0.05$ is statistically significant; ${ }^{*}$ Kruskal Wallis $\mathrm{H}$ test; ${ }^{* *} P$ ure and Applied Arts

Note: $K$-score = average knowledge score; $A$-score = average attitude score; $P$-score = Average practice score 
Table 5: Categorization of study participants score on KAP domains

\begin{tabular}{|c|c|c|c|c|c|c|c|c|c|c|c|c|}
\hline \multirow{2}{*}{$\begin{array}{c}\text { Variable } \\
\begin{array}{c}\text { Gender } \\
\text { Male }\end{array}\end{array}$} & \multicolumn{3}{|c|}{ Knowledge } & \multirow{2}{*}{$\begin{array}{c}\begin{array}{c}P- \\
\text { value }\end{array} \\
0.00\end{array}$} & \multicolumn{3}{|c|}{ Attitude } & \multirow{2}{*}{$\begin{array}{c}\begin{array}{c}P- \\
\text { value }\end{array} \\
0.28\end{array}$} & \multicolumn{3}{|c|}{ Practice } & \multirow{2}{*}{$\begin{array}{c}\begin{array}{c}P- \\
\text { value }\end{array} \\
0.06\end{array}$} \\
\hline & $\begin{array}{c}\text { Good } \\
37\end{array}$ & $\begin{array}{l}\text { Fair } \\
118\end{array}$ & $\begin{array}{c}\text { Poor } \\
59\end{array}$ & & $\begin{array}{c}\text { Good } \\
0\end{array}$ & Fair & $\begin{array}{c}\text { Poor } \\
21\end{array}$ & & $\begin{array}{c}\text { Good } \\
55\end{array}$ & $\begin{array}{l}\text { Fair } \\
125\end{array}$ & $\begin{array}{c}\text { Poor } \\
34\end{array}$ & \\
\hline $\begin{array}{c}\text { Female } \\
\text { Ethnicity }\end{array}$ & 46 & 180 & 21 & & 0 & 0 & 247 & & 49 & 139 & 59 & \\
\hline Malay & 32 & 105 & 28 & & 0 & 0 & 165 & & 39 & 102 & 24 & \\
\hline Chinese & 30 & 98 & 19 & 0.09 & 0 & 0 & 147 & 0.44 & 40 & 84 & 23 & $<0.01$ \\
\hline Indian & 14 & 84 & 27 & & 0 & 1 & 124 & & 22 & 61 & 42 & \\
\hline Others & 7 & 11 & 6 & & 0 & 0 & 24 & & 3 & 17 & 4 & \\
\hline $\begin{array}{l}\text { Marital } \\
\text { status }\end{array}$ & & & & 0.12 & & & & 0.72 & & & & 0.43 \\
\hline Single & 73 & 270 & 66 & & 0 & 1 & 408 & & 91 & 232 & 86 & \\
\hline Married & 10 & 28 & 14 & & 0 & 0 & 52 & & 13 & 32 & 7 & \\
\hline Education & & & & 0.56 & & & & 0.45 & & & & 0.61 \\
\hline Undergrad & 55 & 192 & 47 & & 0 & 1 & 293 & & 67 & 164 & 63 & \\
\hline Postgrad & 28 & 106 & 33 & & 0 & 0 & 167 & & 37 & 100 & 30 & \\
\hline School & & & & 0.00 & & & & 0.35 & & & & 0.03 \\
\hline Hybrid & 28 & 102 & 25 & & 0 & 0 & 155 & & 24 & 91 & 40 & \\
\hline Arts & 12 & 102 & 41 & & 0 & 0 & 155 & & 38 & 86 & 31 & \\
\hline Science & 43 & 94 & 14 & & 0 & 1 & 105 & & 42 & 87 & 22 & \\
\hline Diagnosis & & & & 0.81 & & & & 0.81 & & & & 0.72 \\
\hline Yes & 39 & 16 & 4 & & 0 & 0 & 23 & & 4 & 15 & 4 & \\
\hline No & 80 & 282 & 76 & & 0 & 1 & 437 & & 100 & 249 & 89 & \\
\hline
\end{tabular}

conducted studies in which male gender show low mean score than females $[13,17,18]$.

Although females scored higher than males but still there was no statistically significant difference between attitudes and practices of males and females with only exception of personnel susceptibility of suffering from osteoporosis. The results of Chi-square test revealed that compared to men, females were more concerned about suffering from osteoporosis $(p=0.04)$. A simlar behavior was observed in several previous studies in which men were shown to have the perception that osteoporosis was a female disease [13,16-18].

A common negative attitude that was observed among study participants was low perceived seriousness of osteoporosis compared to cancer and diabetes. Studies have shown that either people believe osteoporosis is an inevitable part of aging and do not take it as a serious disease that may even cause death $[11,21]$ or consider other diseases, i.e., heart diseases, HIV and diabetes more serious than osteoporosis [21]. Although knowledge is a key component in promoting self-care, knowledge alone still cannot result in the practice of preventive behavior or positive attitude [18]. According to health belief model, the individual's perception of a disease and likelihood of adoption of positive attitude and practices depend on four important parameters i.e. perceived seriousness of a disease, perceived susceptibility of a disease, perceived benefits of positive attitude and practice and lastly perceived barriers that might restrain an individual to make positive changes [22].

Similar to findings of other studies, a majority of the participants in the present study have identified lack of calcium and dairy products as a risk factor for osteoporosis while minority had identified genetics or family history as risk factor for osteoporosis [15].

An important finding of the study was the difference in the knowledge of participants on the basis of ethnicity. A statistically significant difference was observed in the level of knowledge of the three ethnic groups included in the study with Chinese scoring maximum in both knowledge and practice section followed by Malays and then Indians. Various studies and statistics have shown that Chinese are at more risk of developing osteoporosis. According to health belief model (HBM), if an individual's susceptibility of suffering from a disease is high, ultimately it would result in adoption of healthy behavior and practices $[22,23]$. As Chinese are at more risk of suffering for osteoporosis, therefore, as indicated by our results, they have more knowledge as well as better attitude and practices towards osteoporosis than other ethnic groups included in this study. 
Another significant finding of the study was that although there was no significant difference between KAP of undergraduates and postgraduates, there, however, was statistically significant difference between knowledge of participants belonging to different schools. Our study shows that students belonging to School of Sciences showed high mean score on knowledge and practices section than students belonging to Schools of Applied and Pure Arts. Some previous studies have correlated the level of education with knowledge of osteoporosis $[9,24]$ but none of them reported any correlation between type of education and knowledge of osteoporosis. This study has attempted to shed some light on this aspect by recruiting study participants from 3 different fields of education. The results clearly showed that type of education has a significant link with knowledge of disease. Contrary to other studies where health care professionals were reported as the source of information by a majority of participants [15], the present study revealed that a minority of participants reported that health care professionals were their primary source of information. This may be due to lack of time on the part of health care professional, ignorance of the seriousness of osteoporosis as a disease or even low level of knowledge among healthcare professionals. Studies that evaluated knowledge of osteoporosis among healthcare professionals surprisingly reported a low level of knowledge especially among nurses who are more often in contact with patients and their families [25].

\section{Limitations of the study}

As mentioned earlier, convenience sampling method was used for filling up of questionnaires and non-respondents were not followed up. Therefore, a better study design could have been adopted using random stratified sampling method. Since the study participants were drawn from one university in Penang, Malaysia, the sample population does not fully represent all university students across Malaysia.

\section{CONCLUSION}

The results of our study demonstrate an urgent need of a targeted educational and awareness program for university students belonging to different age groups. Educational programs based on the four parameters of the health belief model should be designed and implemented on a large scale.

\section{ACKNOWLEDGEMENT}

The authors would like to express their gratitude to students of University Sains Malaysia for their voluntary participation in this work.

\section{CONFLICT OF INTEREST}

None.

\section{REFERENCES}

1. Osteoporosis Prevention, Diagnosis and Therapy. NIH Consensus Statement Online 2000 March 27-29; 17(1): 1-36. [Cited 2012 May 6] Axailable at http://consensus.nih.gov/2000/2000osteoporosis 11 1html.htm

2. Ribeiro V, Blakeley J, Laryea M.. Women knowledge and practices regarding treatment and prevention of osteoporosis. Health Care for Women Int/ 2000; 21(4); 347-353.

3. WHO Scientific Group on the Assessment of Osteoporosis at Primary Health Care Level. Summary Meeting Report. Brussels, Belgium, 5-7 May 2004. [Cited 2012 May 7]. Available at:http://www.who.int/chp/topics/Osteoporosis.pdf| http://www.who.int/chp/topics/Osteoporosis.pdf

4. Lau EM. The Epidemiology of Osteoporosis in Asia. IBMS Bone Key 2009; 6(5): 190-193.

5. Global information hub on integrated medicine (GLOB in Med). [Cited 2012 May 7]. Available at: http://www.globinmed.com/index.php?option=com content\&view=article\&id=77763:Osteoporosis\&ca ${ }^{-} t$ id $=492: 0$

6. Osteoporosis Fact Sheet by International Osteoporosis Foundation (IOF). [Cited 2012 May 7]. Available at; http://www.dolcera.com/wiki/images/Osteoporosis_ factsheet.pdf.

7. , Hafeez F, Zulfiqar S, Hasan S, Khurshid R. An assessment of osteoporosis and low bone density in postmenopausal women. Pak J Physiol 2009; 5(1): 41-44

8. About Osteoporosis by Malaysian Osteoporosis Society. [Cited 2012 May 7]. Available at http://www. osteoporosis. my/aboutOsteo/faq.asp.

9. Dombrowski HT. Effective strategies for the prevention of osteoporosis across the lifespan. J Am Osteopath Assoc 2000; 100: 8-14

10. Kasper MJ, Peterson MG, Allegrante JP. Knowledge, beliefs, and behaviours among college women concerning the prevention of osteoporosis. Arch Fam Med 1994; 3(8): 696-702

11. Ungan $M$, Tumer $M$. "Turkish women knowledge of osteoporosis." Family Practice 2001; 18(2): 199203.

12. Abushaikha L, Omran S, Barrouq L. Osteoporosis knowledge among female school students in Jordan. East Mediterr Health J 15(4): 906-911.

13. Yeap SS, Goh, Gupta ED. Knowledge about Osteoporosis in Malaysian population. Asia Pac J Public Health 2010; 22(2): $233-241$

14. Ali $M$, Tariq SM, Siddiqui $A$, Hussain $N$, Imran $A$. Karachi. J Pak Orth Assoc 2011; 23(2): 112-117

15. Curry LC, Hogstel MO. Risk status related to knowledge of osteoporosis in older women. J Women Aging 2001; 13(2).

16. Waller J, Eriksson O, Foldevi M, Kronhed AC, Larsson L, Lofman O, Toss G, Moller M. Knowledge of osteoporosis in a Swedish municipality-a prospective study. Preventive Med 2002; 34(4): 485-491. 
17. Carlsson L, Johnson CSJ. Osteoporosis health beliefs and practices among Korean immigrants in Nova Scotia. J Immigr Health 2004; 6(2): 93-100

18. Gurney S, Simmonds J. Osteoporosis: a teenage perspective. Physiotherapy 2007; 93(4): 267-272

19. Hasan HARB. Population distribution and basic demographic characteristics 2010. Population and Housing census of Malaysia. [Cited 2012 May 7]. Available at: http://www.statistics.gov.my/portal/ download_Population/files/census2010/Taburan_P enduduk_dan_Ciri-ciri_Asas_Demografi.pdf.

20. Rasoft. [Cited 2012 May 7]. http://www.raosoft.com /samplesize.html

21. Hurst, VPR, Wham CA. Attitudes and knowledge about osteoporosis risk prevention: a survey of New Zealand women. Public Health Nutr 2007; 10(7): 747-753

22. Health belief model. Chapter 4. Theory Essence Sentence, Personnel beliefs influence health behaviors. Jones and Barlett Publishers. [Cited 2012 May 7]. Available at http://www.jblearning. com/samples/0763743836/chapter\%204.pdf.

23. Turner L, Hunt S, Dibrezzo R, Jones C. Design and implementation of an Osteoporosis Prevention Program using the Health Belief Model. [Cited 2012 May 7]. Available at: http://findarticles.com/ p/articles/mi mOCTG/is 2 19/ai n6361768/

24. Nguyen NV, Dinh TA, Ngo QV, Tran VD, Breitkopf CR. Awareness and Knowledge of Osteoporosis in Vietnamese Women. Asia Pac J Public Health. 2011 Nov 14. PMID: 22087035

25. Chen I.J, Shu Yu, Tze-Fang Wang, Shun-Ping Cheng and Lian-Hua Huang. Knowledge about osteoporosis and its related factors among public health nurses in Taiwan. Osteoporos Int .2005; 16(2): $2142-2148$ 